\title{
Gross Anatomical and Scanning Electron Microscopic Study of Reticulum of Sheep (Ovis aries) during Pre-natal Period
}

\author{
Ritun Patra $^{1 *}$, Uma Kanta Mishra ${ }^{1}$ and Choudhury Deepak R. Mohapatra ${ }^{2}$ \\ ${ }^{1}$ Department of Veterinary Anatomy \& Histology, C. V. Sc. \& A. H., OUAT, \\ Bhubaneswar, India \\ ${ }^{2}$ Additional Veterinary Assistant Surgeon, Tigiria, Cuttack, India \\ *Corresponding author
}

\section{A B S T R A C T}

\section{Keywords}

Sheep, Reticulum,

Pre-natal

Article Info

Accepted:

17 October 2019

Available Online:

10 November 2019
A study was undertaken to elucidate the gross anatomical development of reticulum of sheep during pre-natal period. For this study 12 foeti were divided into three groups i.e. Group I (0-50 days of gestation), Group II(51-100 days of gestation) and Group III(101-150 days of gestation) with 04 foeti in each group. By 32 days of gestation, the reticulum was clearly visible as a distinct compartment and it was completely concealed by the left lobe of the liver at all stages of gestation. It was positioned ventro-caudal to the rumen and revealed a pear shape at 32 days of gestation. In foeti of 32 and 48 days of age, it was observed to be located between rumen and omaso-abomasum, then it gradually shifted to left of the median plane and positioned as anterior most compartment of the stomach. It was positioned between $7^{\text {th }}$ and $9^{\text {th }}$ rib at terminal age of the foetal life. The surface of the reticulum appeared smooth and pale between 32 and 67 days of gestation. The tiny mucosal projections i.e. the primary reticular folds were noted at 75 days of gestation. The distinct hexagonal honey comb pattern was evident at 94 days of gestation.

\section{Introduction}

Livestock is one of the fastest growing subsector of Indian Agriculture. Among the livestock, sheep plays an important role contributing to the rural economy in the form of wool, meat, milk, skin and manure. This small ruminant has the ability to use the grazing pasture of any kind and quality even the poorest of the poor pasture, into its production traits (Franco et al., 2004). Sheep is popular for mutton and wool in the Indian sub-continent and it has the potential to convert its diet into the musculo-skeletal components of the body through a guided metabolic consortium of the physiology of digestion. The gastro intestinal hepato-portal system is the key pathway for metabolic 
turnover of assimilated food into flesh yield. The ruminant stomach has four separate compartments i.e. rumen, reticulum, omasum and abomasum, whereas the first three chambers are regarded as the fore stomach and the last chamber is termed as the glandular stomach.

The ruminant stomach is significant for its ability to transform low quality forage into products of great nutritional value (Lombardi, 2005).

Each compartment has its own morphological particularities and characterized by certain unique gross and histological features (Schummer and Nickel, 1975) reflecting its morphological and functional adaption to ingestion, processing and digestion of plant material.

During pre-natal life the ruminant stomach undergoes certain morphological changes in order to meet functional demands in post-natal life. These morphological changes are related to the growth and development of gastric viscera (Garcia et al., 2014).

The current literature reveals that reports on development of the reticulum (Franco et al., 1993, Regodonet al., 1997 and Soniet al., 2016) of the pre-natal sheep are gravely scanty. One of the major limitations on such studies is probably the paucity of the availability of the embryos and foeti at all ages of the gestation. Systemic reports on gross and electron microscopic development of reticulum have not been elucidated so far in case of sheep embryos and foeti and thus there is a lack of comprehension. Therefore the present study was undertaken to trace the macro anatomical development of the reticulum during pre-natal period. Scanning electron microscopy was used to make comparative studies of the reticular mucosa during this prenatal period.

\section{Materials and Methods}

\section{Experimental animal}

For this study 12 apparently healthy and normal embryos/foeti of either sex of nondescript breed of sheep were collected from the local slaughter house located at Jadupur and Laxmisagar, Bhubaneswar. These foeti were cleaned with wet cotton to remove the adherent amniotic fluid. Each foetus was measured for its crown rump length (CRL) in centimetres $(\mathrm{cm})$ with the help of nonstretchable nylon thread and graduated scale and the CRL was placed on the standard CRLGestation Age Curve put forth by Noden and Lahunta (1985) to estimate the approximate age of foeti in days.

\section{Experimental design}

The experiment was designed to note the changes in the macro anatomy of the reticulum of the sheep foeti during pregnancy at three phases i.e. early pregnancy ( 0 to 50 days of gestation, Group-I), mid-pregnancy (51 to 100 days of gestation, Group-II) and late pregnancy (101 to 150 days of gestation, Group-III). Each group comprised of four numbers of foeti i.e. foeti with gestation age of $32,37,44$ and 48 days were studied under Group-I; foeti with gestation age of 63, 67, 75 and 94 days were studied under Group-II; and foeti with gestation age of $111,116,121$ and 150 days were examined under Group-III. Following the harvest of the embryo/foeti from the gravid uterus, their abdomen was opened to explore the reticular compartment for record of its gross morphological and scanning electron microscopic observations.

\section{Gross morphological study}

The abdominal cavity of the foetus was cutopen by giving a longitudinal ventro-median incision. The stomach of the fetus was then 
exposed by carefully reflecting the lobes of the liver and then in-situ relationship of the reticular compartment with adjacent abdominal viscera and topography of this chamber in relation to ribs and vertebrae were recorded. Its shape and colour were noted. The reticulum was then cut open to expose its interior by incising the greater/lesser curvatures for record of internal observations.

Thereafter, tissue pieces from the reticulum was excised for Scanning Electron Microscopic (SEM) study at Central Lab, Odisha University of Agriculture \& Technology, Bhubaneswar-751003 (Scanning Electron Microscope, Make: Hitachi and Model: S-3400N) and the electronphotomicrographs were recorded.

\section{Results and Discussion}

The developing reticulum was found to be concealed by the left lobe of the liver at all ages of gestation in the present investigation. The reticulum was ventro-caudal to the rumen and revealed a pear shape at 32 days of gestation. The reticulum appeared as a spherical sac like structure at 48 days of gestation and this shape remained static till terminal stage of the foetus. The constriction between reticulum and omaso-abomasum was distinct. Its lower $2 / 3^{\text {rd }}$ part was noted to remain in contact with the omasum and anterior part of the abomasum.

The reticulum was observed to lie on the left side of the abdominal cavity between 32 and 48 days of gestation. In foeti of 32 and 48 days of age, it was observed to be located between rumen and omaso-abomasum. In foeti aged 63 and 150 days of gestation, the reticulum gradually shifted to left of the median plane and positioned as the anterior most compartment of the stomach (Fig. 1 and 2 ). The topography of reticulum was from $11^{\text {th }}$ rib to $2^{\text {nd }}$ lumbar vertebra at 32 days of gestation and changed to $11^{\text {th }}$ to $13^{\text {th }}$ rib at 48 days of gestation. Between 63 and 75 days of gestation, its topography was noted to be $11^{\text {th }}$ to $12^{\text {th }}$ rib. At 94 days of gestation it was located between $7^{\text {th }}$ rib and $9^{\text {th }}$ intercostal space. This topographic position of the developing reticulum remained constant up to 121 days of gestation. The reticulum was positioned between $7^{\text {th }}$ and $9^{\text {th }}$ rib at terminal age of the foetal life.

The internal surface of the reticulum appeared to be smooth and pale between 32 and 67 days of gestation. The appearance of tiny mucosal projections, this would be primary reticular folds or crests of the future, were noted at 75 days of gestation. At this age the surface appeared to be white in colour and it remained constant up to 150 days of gestation. The distinct hexagonal honey comb pattern due to arrangements of primary reticular folds was distinct at 94 days of gestation (Fig. 3). The honey comb feature stood out prominently with advancement of age (Fig. 4). By 94 days of gestation, small conical projections i.e. the corial (conical) papillae were observed both on the mucosal surface of the reticular folds as well as on the mucosa of wall of the reticulum. The secondary reticular folds within the hexagonal honey comb were seen at 116 days of gestation and gradually they became tall with advancement of age. The height of the secondary reticular folds was small and the height of the primary reticular folds was large.

The scanning electron microscopic observation revealed development of primary reticular folds at 48 days of gestation without definite pattern of their arrangement (Fig. 5). With advancement of age, these primary reticular folds became large in height and were arranged in a definite pattern to establish the specific hexagonal honey comb appearance at 75 days of gestation. The secondary reticular folds and papillae on the mucosal surface of the folds and reticular wall 
appeared at 94 days under the scanning electron microscope (Fig. 6). With advancement of age the height of primary and secondary reticular folds and mucosal papillae got large as observed by scanning electron microscope (Fig. 7 and 8).

Fig.1 Photomicrograph showing the growing compartments of the stomach i.e. rumen (Re), reticulum (Rt), omasum (O), abomasum (A), esophagus (E) and duodenum (D) of sheep foetus aged 63 days. Note that the reticulum is present as the anterior most compartment of the stomach

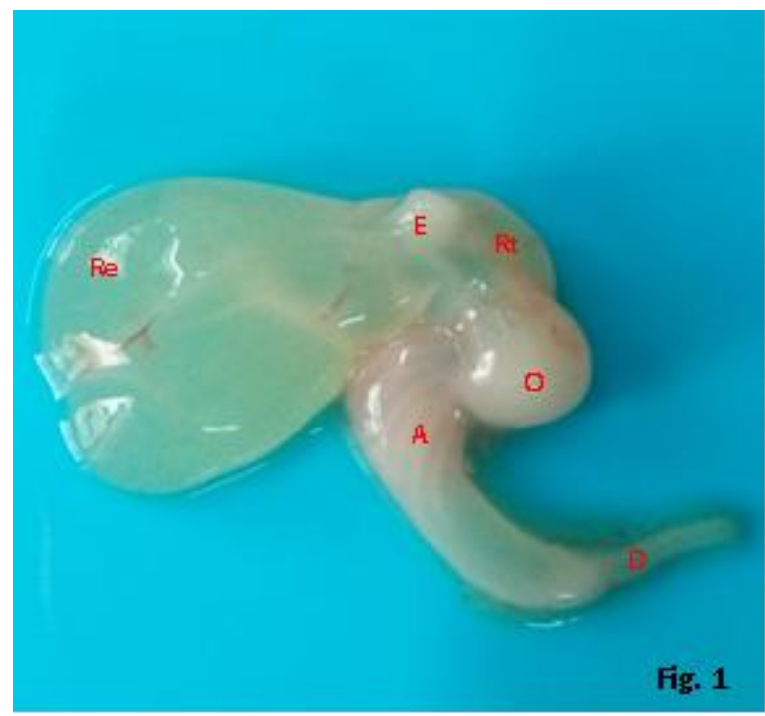

Fig.2 Photomicrograph showing the growing stomach of sheep foetus aged 94 days. Note the whitish colour of reticulum (Rt) and omasum $(\mathrm{O})$, a light brown to grey colour of the rumen $(\mathrm{Re})$ and abomasum (A)

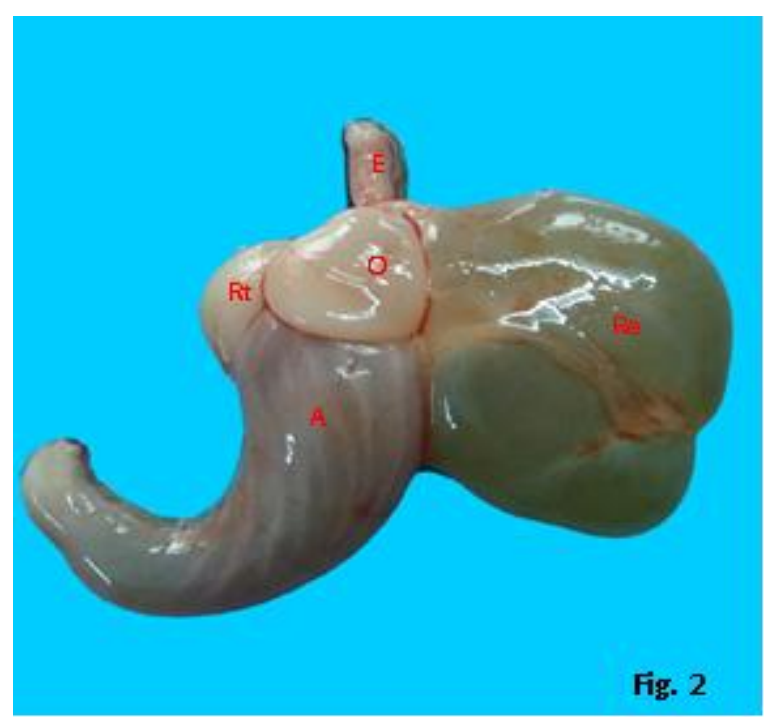


Fig.3 Photomicrograph showing the faint appearance of the reticular folds on the mucosal surface of the reticulum of sheep foetus aged 94 days

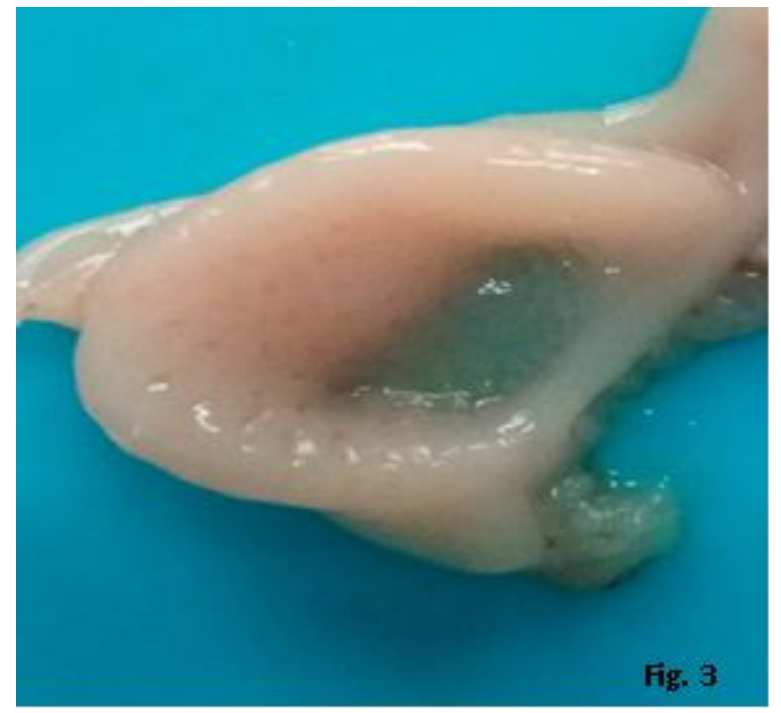

Fig.4 Photomicrograph showing distinct honey comb pattern on the mucosa of reticulum in sheep foetus aged 150 days

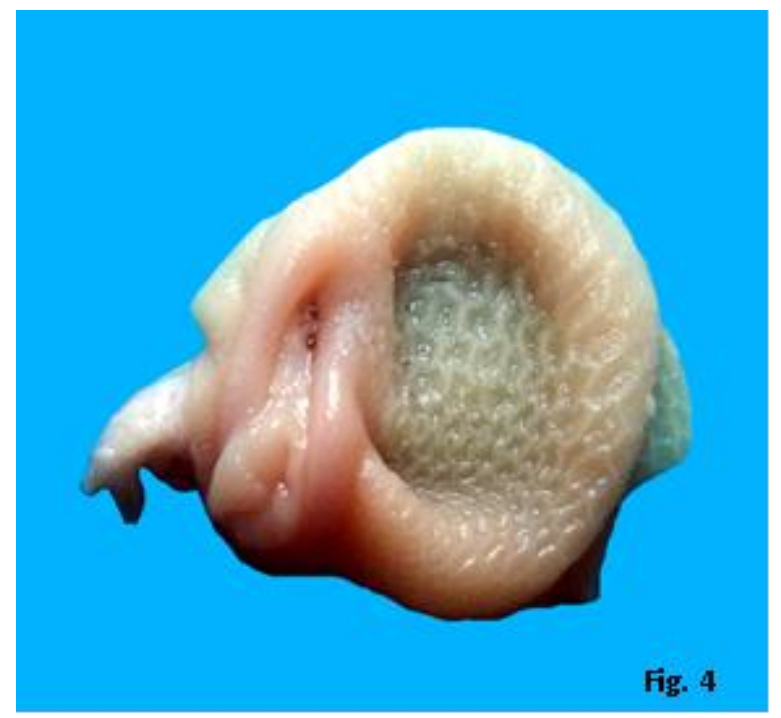


Fig.5 Photomicrograph showing the initial organization of primary reticular folds (arrow) on the mucosal surface of reticulum without formation of distinct honey combs of sheep foetus aged 48 days. Scanning electron micrograph $\times 5.00 \mathrm{kv}$

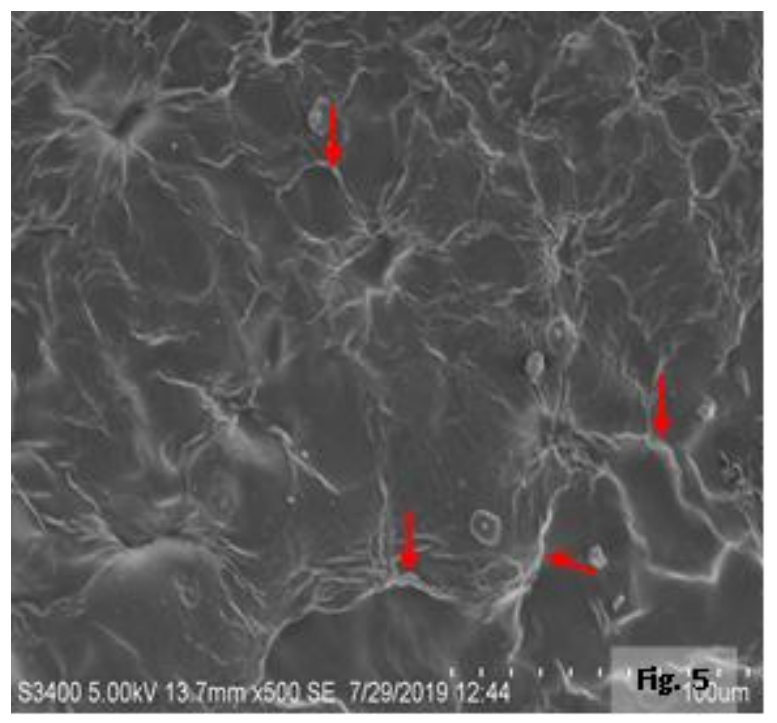

Fig.6 Photomicrograph showing the formation of honey comb mucosa by the primary reticular folds $(\mathrm{P})$ of the reticulum of sheep foetus aged 94 days. Note the secondary reticular folds (arrow) within the honey comb. Scanning electron micrograph $\times 5.00 \mathrm{kv}$

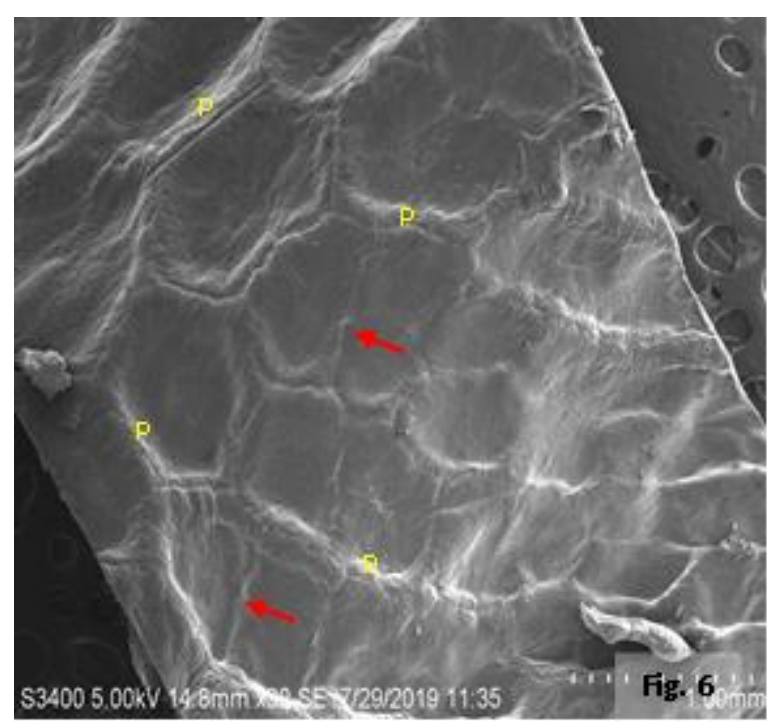


Fig.7 Photomicrograph showing the morphology of honey comb on the mucosal surface of reticulum of sheep foetus aged 150 days. Scanning electron micrograph $\times 5.00 \mathrm{kv}$

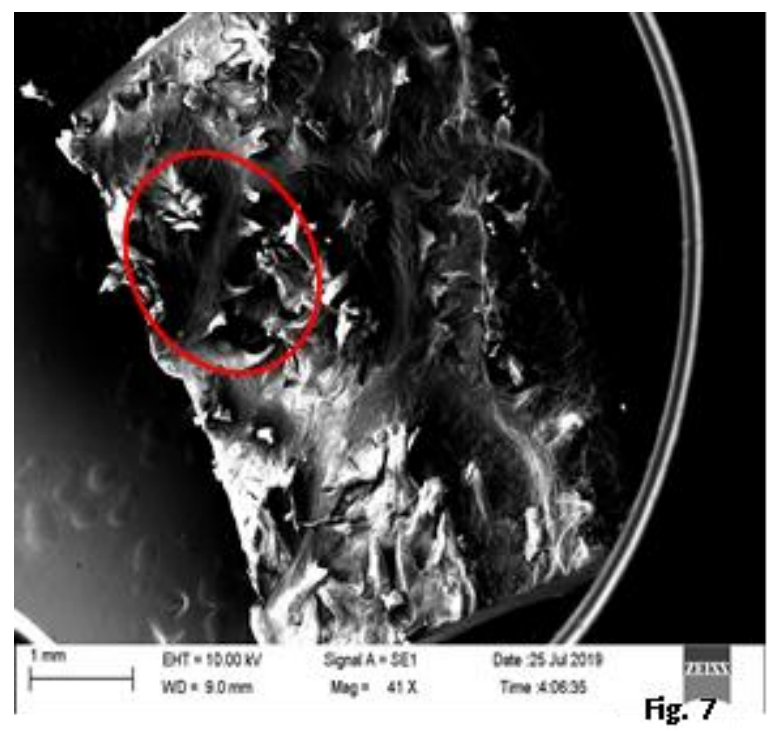

Fig.8 Photomicrograph showing the primary $(\mathrm{P})$ and secondary $(\mathrm{S})$ reticular folds of the honey comb mucosa of reticulum of sheep foetus aged 150 days. Scanning electron micrograph $\times$ $5.00 \mathrm{kv}$

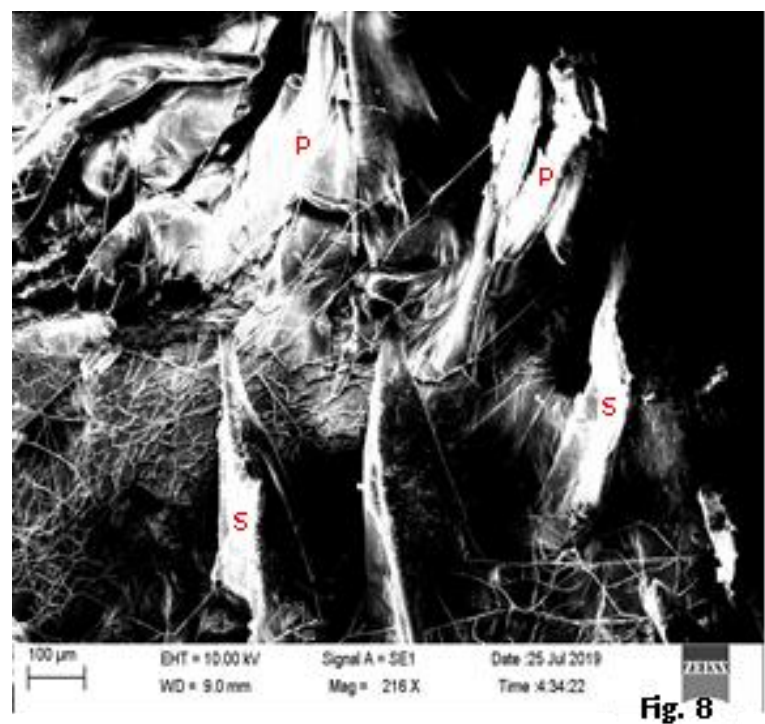

The developing reticulum was seen to be concealed by the left lobe of the liver at all ages of the sheep foetus. It was located ventrocaudal to the rumen and had a pear shape at 32 days of gestation. With progress of foetal age, the shape of the reticulum changed from pear shape to a spherical sac. Similar findings were also observed by Gupta et al., (2016) in goat. In contradiction to the findings of the present study, Panchamukhi (1973) observed the reticulum to be triangular shape in buffalo foeti at CRL $3.5 \mathrm{~cm}$. The demarcation between reticulum and omaso-abomasum was distinct. The reticulum was observed to lie on 
the left side of the abdominal cavity between the rumen and omaso-abomasum by $32-48$ days of gestation. In foeti aged 63-94 days of gestation, the reticulum shifted slightly to left of the median plane and by 111 to 150 days of foetal age, it got positioned as the anterior most compartment of the stomach. The topographic change in position of rumen pushed the reticulum to the cranio-ventral position (Roy, 2009). The reticulum was positioned from $11^{\text {th }}$ rib to $2^{\text {nd }}$ lumbar vertebra covering about two intercostal spaces, one costo-lumbar space and one inter-lumbar space at 32 days of gestation and changed to $11^{\text {th }}$ and $13^{\text {th }}$ rib at 48 days of gestation, thereby reflecting a squeezed size of the reticulum. Between 63 and 75 days of gestation, the topography was noted to be $11^{\text {th }}$ to $12^{\text {th }}$ rib occupying single intercostal space. It may be due to the orientational changes and due to faster growth of the reticulum along the dorso-ventral axis than the cranio-caudal axis at this particular age of gestation. At 94 days of gestation, it was located between $7^{\text {th }}$ rib and $9^{\text {th }}$ intercostal space which continued up to 121 days of gestation. Finally the reticulum was positioned between $7^{\text {th }}$ and $9^{\text {th }}$ rib at term end. These topographic observations of reticulumin the present study are in partial agreement with the findings of Gupta et al., (2016) in goat during pre-natal period.

The internal surface of the reticulum appeared smooth and pale between 32 and 67 days of gestation and whitish in colour between 75 and 150 days of gestation. The tiny mucosal projections i.e. this would be primary reticular folds, first appeared at 75 days of gestation. Due to developmental changes, the primary folds became distinct at 94 days of gestation and there was formation of secondary folds by 116 days of gestation. These reticular folds then got organized to establish the characteristic honey comb like pattern of the reticular mucosa. Conical papillae were first observed on the mucosal surface of the reticular folds as well as on the mucosal wall of the reticulum by 94 days of gestation and gradually became prominent. These conical papillae are believed to offer roughness to the mucosal surface for better grinding of the food particles. Gupta et al., (2016) observed the appearance of tiny pin point projections, the presumptive reticular folds first at 76 days of gestation in goat foetus which is a day later the age noted in the present findings. The author also observed the first appearance of conical papillae at 112 days of gestation in goat which was observed to be 116 days in sheep of the present study, indicating a late appearance of the papillae in sheep.

The gross anatomical observations and scanning electron microscopic analysis of the reticulum of sheep during pre-natal period indicates that the age and diet are the influencing factors in the structural development of reticulum.

\section{References}

Franco AJ, Redondo E and Masot AJ. (2004b) Morphometric and immunohistochemical study of the reticulum of red deer during prenatal development. J. Anatomy.205: 277289.

Lombardi G. (2005) Optimum management and quality pastures for sheep and goat in mountain areas. Options mediterraneennes. 67: 19-29

Garcia A, Rodriguez P, Masot J, Franco A and Redondo E. (2014) Histomorphometric study of the goat stomach during prenatal development. Ani. Sci. J. 85: 951-962.

Schummer A and Nickel R. (1975) Lehrbuch der Anatomie der Haustiere, $3^{\text {rd }}$ edn.Vol-II, Verlag. Pp 149-173, Paul Parey, Berlin.

Franco A, Robina A, Regodón S, Vivo JM, 
Masot AJ and Redondo E. (1993a) Histomorphometric analysis of the reticulum of the sheep during development. Histol. \& Histopathol. 8(3): 547-556.

Regodon S, Franco A, Masot AJ and Redondo E. (1997). Comparative Analysis of the Epithelium of the Non-glandular Stomach Compartments of Merino Sheep during Development. Anat. Histol. Embryol. 25: 233-241.

Soni T, Goswami H and Panchal KL. (2016) Prenatal Development of ForeStomach in Small Ruminants. Adv. in Life Sci. 5(22): 10209-10215.

Noden DM and Lahunta AD. (1985) Embryology of Domestic Animals: Developmental Mechanisms and Malformations. Williams \& Wilkins,
Berlin.

Panchamukhi BG. (1973) Prenatal development of the buffalo (Bubalus bubalis) stomach with particular reference to organogenesis and histogenesis, Ph D thesis submitted to Department of Anatomy, Gujarat College of Veterinary Science and Animal Husbandry, Anand, India.

Gupta V. (2016) Morphological, Histological and Histochemical studies on the stomach of pre-natal goat. Ph.D thesis submitted to U.P. Pandit Deen Dayal Upadhaya Pashu Chikitsa Vigyan Vishwavidyalayaevem Go-Anusndhan Sansthan, Mathura-281001.

Roy KS. (2009) Fundamentals of Veterinary Embryology, $\quad 1^{\text {st }}$ edn., Kalyani Publishers, New Delhi.

\section{How to cite this article:}

Ritun Patra, Uma Kanta Mishra and Choudhury Deepak R. Mohapatra. 2019. Gross Anatomical and Scanning Electron Microscopic Study of Reticulum of Sheep (Ovis aries) during Pre-natal Period. Int.J.Curr.Microbiol.App.Sci. 8(11): 2049-2057. doi: https://doi.org/10.20546/ijcmas.2019.811.237 